\title{
Review
}

\section{Health problems of adolescent and adult patients with 21-hydroxylase deficiency}

\author{
Toshihiro Tajima ${ }^{1}$ \\ ${ }^{1}$ Jichi Medical University Children’s Medical Center Tochigi, Tochigi, Japan
}

\begin{abstract}
Twenty-one-hydroxylase deficiency (21-OHD) is one of the most common forms of congenital adrenal hyperplasias. Since the disease requires life-long steroid hormone replacement, transition from pediatric clinical care to adolescent and adult care is necessary. Recently, several studies have shown that morbidity and quality of life in adolescent and adult patients with 21-OHD are impaired by obesity, hypertension, diabetes mellitus, impaired glucose tolerance, dyslipidemia, and osteoporosis. In addition, excess adrenal androgen impairs fertility in both females and males. This mini review discusses the current health problems in adolescent and adult patients with 21-OHD and ways to prevent them.
\end{abstract}

Key words: 21-hydroxylase deficiency, adolescent, adult, obesity, fertility

\section{Introduction}

The most common form of congenital adrenal hyperplasia is 21-hydroxylase deficiency (21-OHD), which affects about 1 in 18,000 worldwide (1-3). This disease is classified into three subtypes according to its severity. The most severe form is the salt-wasting (SW) form caused by glucocorticoid and mineralocorticoid deficiencies. SW females express virilized external genitalia (VEG) together with low serum sodium levels. The simple virilizing (SV) form also presents with VEG in affected female neonates, but aldosterone synthesis is not

Received: April 16, 2018

Accepted: July 2, 2018

Corresponding author: Toshihiro Tajima, MD, PhD, Jichi Children's Medical Center Tochigi, 3311-1 Yakushiji, Shimotsuke-shi, Tochigi 329-0498 Japan

E-mail: t-tajima@jichi.ac.jp

This is an open-access article distributed under the terms of the Creative Commons Attribution Non-Commercial No Derivatives (by-nc-nd) License. (CC-BY-NC-ND 4.0: https:// creativecommons.org/licenses/by-nc-nd/4.0/) impaired. Nonclassic (NC) is the mildest form and can manifest as hyperandrogenism later in life (3). These phenotypic differences are mainly due to the genotype of the 21-hydroxylase gene (CYP21A2) (1-5).

Patients with SW and SV forms require lifelong steroid replacement. During the pediatric period, the main targets for treatment are normal physical growth, normal development of secondary sex characteristics, and the avoidance of adrenal crisis $(1,3)$. However, in adolescents and adults, growth is no longer a concern. Instead, the main targets for treatment are shifted to normal fertility and the prevention of metabolic health problems (6-8).

After 1950, the disease prognosis improved due to the introduction of glucocorticoid and mineralocorticoid treatments; however, current glucocorticoid replacement therapy is not ideal. Excessive androgen from the adrenal gland is sometimes difficult to suppress with glucocorticoid treatment and this results in precocious puberty and short stature in boys 


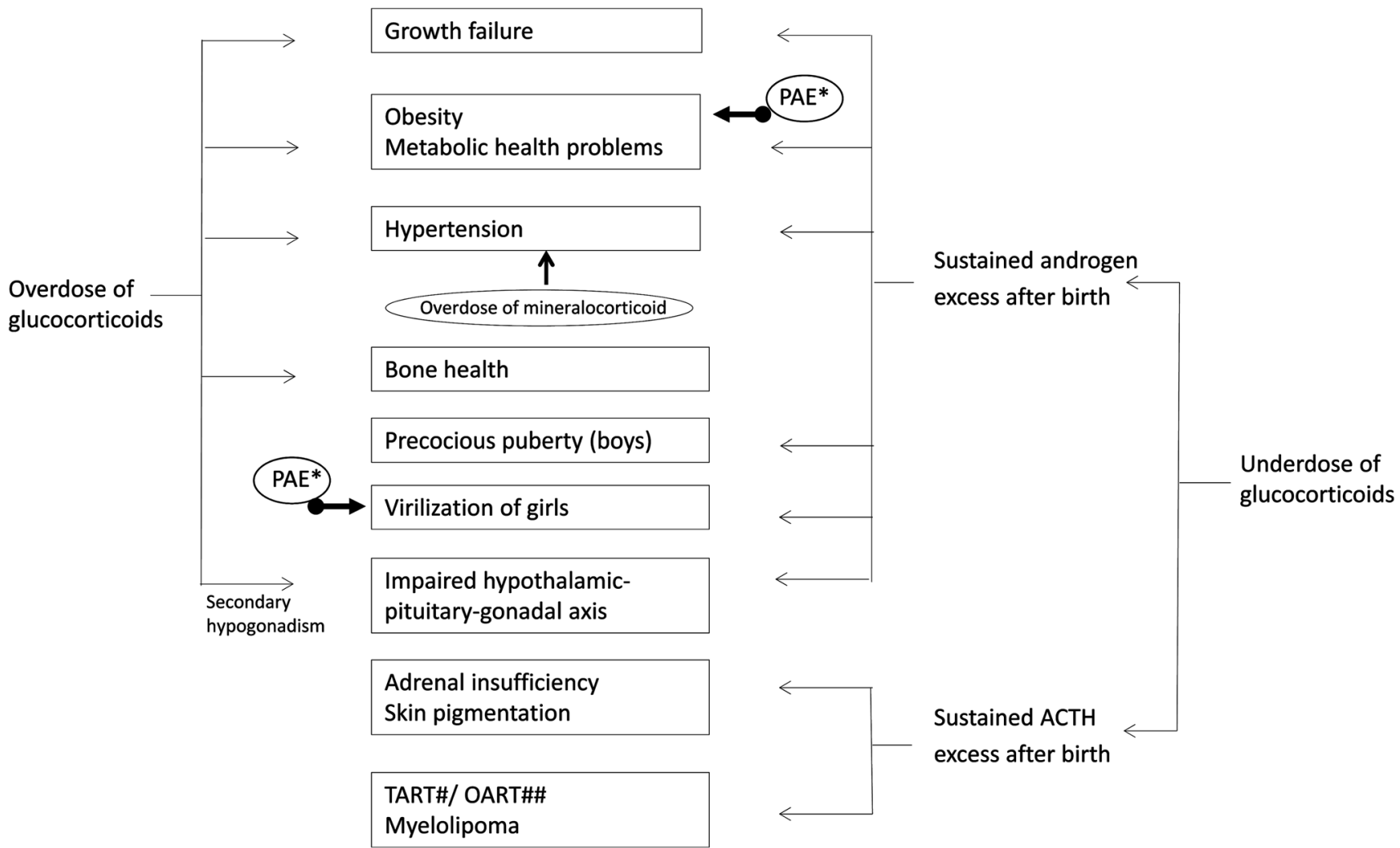

Fig. 1. Endocrine imbalances in 21-OHD. * PAE: Prenatal androgen excess. \# TART: Testicular adrenal rest tumor. \#\# OART: Ovarian adrenal rest tumor. Prenatal androgen excess causes virilization of the female fetus. In addition to high postnatal androgen, high prenatal levels of androgen from the adrenal gland may be related to the development of obesity, insulin resistance, and metabolic problems (bold arrow).

and virilization and short stature in girls. To suppress adrenal androgen, supraphysiological doses of glucocorticoids are necessary (1, 3, 6-8); however, these induce iatrogenic Cushing features, resulting in metabolic health problems (1, 3, 6-8). Achieving a glucocorticoid balance is very difficult.

This mini review discusses the current health problems in adolescent and adult patients with 21-OHD and ways to prevent them.

\section{Metabolic and Cardiovascular Issues}

Health problems associated with patients with 21-OHD are summarized in Fig. 1. To date, several studies have shown an increased risk of obesity, hyperlipidemia, and hypertension in adolescent and adult patients with 21-OHD (9-12). Finkelstein et al. (9) reported the clinical features of 244 adult patients with 21-OHD in the United States. In this study, approximately $30 \%$ of patients were obese and $18 \%$ had metabolic syndrome. From a study in the United Kingdom, Arlt et al. (10) reported that in adults with 21OHD, obesity was observed in $42 \%$ of patients, hypercholesterolemia in $46 \%$, and insulin resistance in 29\%. In addition, women with SW and SV 21-OHD had higher diastolic blood pressure than age- and sex-matched controls. Falhammar et al. (11) presented 21-OHD data from adults in Sweden. According to their study, the frequency of hypertension, hyperlipidemia, atrial fibrillation, and venous thromboembolism were higher than those of control groups. In 
addition to hypertension, impaired vascular endothelial and smooth muscle function was observed in adolescents with 21-OHD $(13,14)$.

From Japan, Matsubara et al. (15) reported data on the growth and body composition of children with 21-OHD. Body mass index (BMI) both in male and female patients increased and adiposity rebound occurred earlier in patients compared with healthy Japanese children. Furthermore, the same Japanese group reported that lower body weight and BMI at birth were related to early adiposity rebound and suggested that prenatal androgen excess may affect the early adiposity rebound (16). Early adipose rebound in children with 21-OHD has also been reported by Sarafoglou et al. (17). It is well recognized that early adiposity rebound is associated with future obesity $(18,19)$; however, the mechanism of early adipose rebound in children with 21 OHD has not yet been clarified. Additionally, life style intervention for prevention of obesity in children with 21-OHD is also important.

Several hypotheses have been proposed for developing obesity; 1) glucocorticoid excess, 2) postnatal androgen excess, and 3) prenatal androgen excess (Fig. 1).

Regarding glucocorticoid excess, the current replacement therapy is not ideal. Since the current glucocorticoid regimen is usually divided into three doses (morning, daytime, and evening), it is impossible to mimic the normal circadian rhythm of the ACTH-cortisol axis thereby preventing the early morning surge of ACTH, which is the main driver of excess androgen secretion from the adrenal gland (3, $7,8)$. To obtain good control, a glucocorticoid dose higher than the physiological dose is required. As a result, high serum cortisol levels lead to Cushing features and several additional health problems (Fig. 1). To solve these problems and mimic physiological cortisol secretion, a modified release formulation of hydrocortisone has recently been developed and clinical trials of this drug have been reported (20,21). According to these studies, twice-daily administration of this drug achieved a dual rhythm of cortisol secretion, remarkably similar to physiological cortisol secretion. Furthermore, this medication can suppress 17-hydroxyprogesteron and adrenal androgen much better than the conventional glucocorticoid regimen. This finding is promising for the development of a glucocorticoid replacement regimen for 21-OHD.

Knowles et al. (22) reported on the clinical presentations of children with 21-OHD in the United Kingdom, aged 1-15 yr, where neonatal mass screening for congenital adrenal hyperplasia is not performed nationwide. In this study, $21 \%$ of boys and $41 \%$ of girls were obese at the time of the first diagnosis prior to glucocorticoid treatment. It has also been reported that decreased insulin sensitivity is associated with hyperandrogenism in untreated patients with NC form of 21-OHD $(23,24)$. In addition, insulin resistance was also found in women with polycystic ovary syndrome (PCOS) with hyperandrogenism (25). These findings indicate that excess adrenal androgen may induce insulin resistance and obesity. Furthermore, several animal studies suggest that prenatal hyperandrogenism affect fetal programming, resulting in insulin resistance, dyslipidemia, cardiovascular disease, and metabolic syndrome $(26,27)$. Taken together, these data suggest that patients with 21-OHD have an increased risk of obesity independent of glucocorticoid therapy, due to pre- and postnatal adrenal androgen excess.

Hypertension can be caused by an overdose of glucocorticoids which can also involve mineralocorticoids. Mineralocorticoids are used in the treatment of SW 21-OHD. In the SV form, there may be a subclinical aldosterone deficiency, and mineralocorticoids may be beneficial in maintaining serum sodium and decreasing ACTH and vasopressin, resulting in a lower glucocorticoid dosage (3). An Endocrine Society Clinical Practice Guideline recommends that mineralocorticoids should be used in all patients with 21-OHD during early infancy (3). Bonfig et al. (28) reported that $45 \%$ of these 
(A)

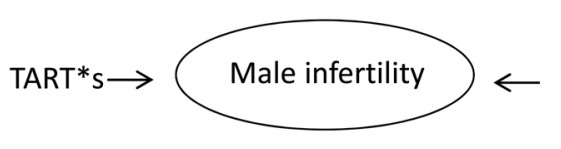

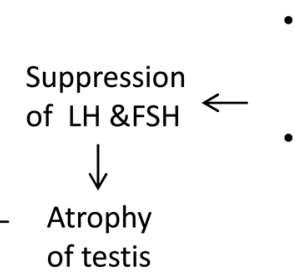

- Sustained excess androgen from the adrenal gland

- Overdose of glucocorticoids

(B)

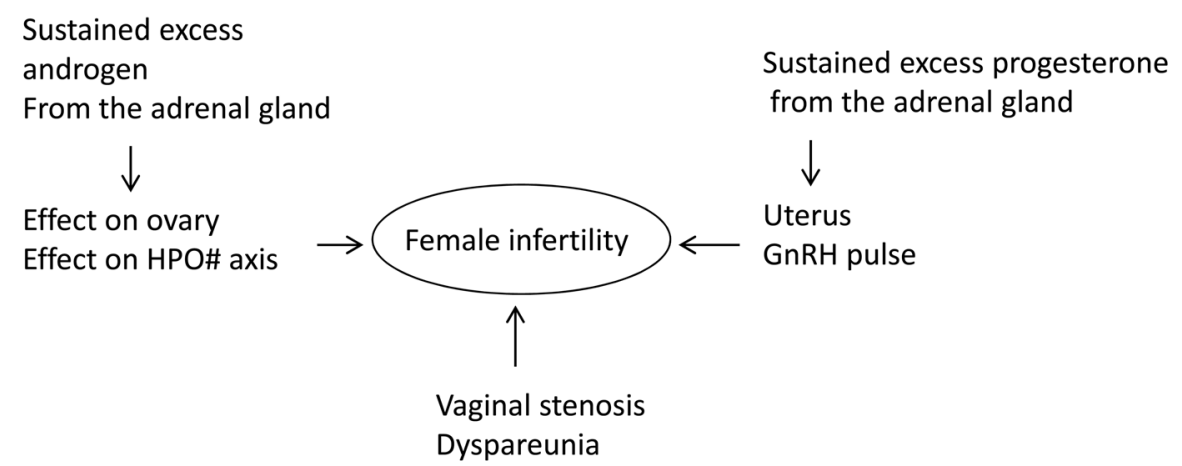

Fig. 2. (A) Factors affecting male infertility. In adult males with 21-OHD, TARTs are frequently observed, affecting male fertility. (B) Factors affecting female infertility. In females, excess androgen and progesterone from the adrenal gland affects the ovaries, hypothalamic-pituitary-ovarian axis, and the uterus, resulting in infertility. In addition, vaginal insufficiency with dyspareunia after surgery is related to a low fertility rate. ${ }^{*}$ TART: Testicular adrenal rest tumor. \# HPO: Hypothalamic-pituitaryovary.

patients had increased systolic blood pressure during the first year of life and 15\% were still hypertensive at $2 \mathrm{yr}$ of age. They suggested that hypertension in these children is probably caused by mineralocorticoid excess $(28,29)$. Therefore, to avoid mineralocorticoid excess, close monitoring of blood pressure and plasma renin activity are mandatory not only in adolescent and adult patients, but also from infancy to childhood.

\section{Fertility in Male Patients}

Male fertility in patients with 21-OHD is impaired when disease control is poor. A recent French study reported that severe oligospermia or azospermia was found in $42 \%$ of male patients. There are several reasons for male infertility (Fig. 2A). First, excess androgen from the adrenal gland impairs testicular function, suppressing
LH and FSH, resulting in testicular atrophy. Second, testicular adrenal rest tumors (TARTs) may be involved. TARTs have been found in $20 \%$ to $50 \%$ of male patients with classical 21 OHD (12, 30-32). The pathogenesis of TART is considered to involve adrenocortical primordial cells, which aberrantly move into the testis or reprogram Leydig cell precursors (30-32). TARTs destroy normal testicular tissue and cause compression of the seminiferous tubules leading to obstructive azospermia.

\section{Fertility in Female Patients}

Adult females with 21-OHD are at risk of oligomenorrhea, chronic anovulation, and infertility (33-35). These symptoms are caused by multiple factors (Fig. 2B) (33-35), one being the direct effect of adrenal androgen on the ovaries. 
Androgens induce enlarged multicystic ovaries and theca interstitial hyperplasia in 21-OHD (34). Female-to-male trans-sexual individuals with testosterone administration also develop polycystic ovaries (36). Secondly, a high serum androgen level is thought to impair the normal hypothalamic-pituitary-ovarian (HPO) axis. A study of females with NC 21-OHD showed an increase in LH release (37), resulting in ovarian dysfunction, similar to that observed in polycystic ovary syndrome (33-35). Thirdly, excess progesterone from the adrenal gland also affects reproductive function. It has been reported that high levels of progesterone impair endometrial receptivity and decidualization (38). In addition, gender dysphoria and vaginal insufficiency with dyspareunia after surgery, have been related to a low fertility rate $(39,40)$. Finally, overdoses of glucocorticoids also induce hypogonadotropic hypogonadism due to the inhibitory effect on the hypothalamic control of gonadotropin secretion (41).

\section{Tumors in Adults with 21-OHD}

While TARTs are frequently observed in adult male patients, ovarian adrenal rest tumors (OARTs) are rare in comparison (6-8). In one small study, 15 female adult patients were evaluated by ultrasonography and magnetic resonance imaging and no cases of OARTs were found (42). These female patients were regularly followed while hospitalized and good control of the disease was achieved. OARTs were usually found when 21-OHD disease management was very poor and an adrenalectomy was performed $(43,44)$.

Adrenal myelolipoma has also been reported in patients with 21-OHD (45-48). Myelolipoma is a benign tumor composed of myeloid tissue and it is thought that sustained high ACTH levels may play a role in the growth of this tumor. In one study, $6 \%$ of adult patients with $21-\mathrm{OHD}$ had myelolipomas, but none had malignant tumors (47). Since myelolipomas are benign, resection is not necessary, but in cases of very large or bilateral tumors they may be surgically removed $(45,46,48)$.

\section{Bone Problems}

Glucocorticoids are used therapeutically for several diseases such as autoimmune, rheumatic, kidney, gastrointestinal, and endocrine disorders. Since excess glucocorticoids cause osteopenia and osteoporosis, patients with 21-OHD have an increased risk for these conditions (49). Currently, controversies exist concerning bone health in adolescent and adult patients with 21OHD. A study from the United States showed that $37 \%$ of adult patients had low bone mineral density (BMD) (9). In a study of adult patients with 21-OHD from the United Kingdom, 40\% of patients exhibited osteopenia while $7 \%$ had osteoporosis (10). On the other hand, Koetz et al. (50) reported normal lumbar spine BMDs in patients with 21-OHD. Ceccato et al. (51) also reported that lumbar spine BMDs was similar to that of age-matched controls. Furthermore, they showed there was no relationship between glucocorticoid dosage and lumbar spine BMDs.

These contradictory results may be due to heterogeneous populations, disease types, age, and glucocorticoid treatment regimens. While it has not been possible to draw a definitive conclusion regarding bone loss in patients with $21-\mathrm{OHD}$, it is important to keep in mind that osteopenia and osteoporosis may occur due to their lifelong treatment with glucocorticoids.

\section{Hormonal Evaluation of Adolescents and Adults}

Seventeen-hydroxyprogesterone (17-OHP) is a standard marker of glucocorticoid dose and presumably androgen excess in children and adults, but the correlation between 17-OHP and adrenal androgen is thought to be variable in adults (6-8). In both male and female children and adults, normal and suppressed 17-OHP 
levels indicate glucocorticoid overdose. Merke et al. $(6,8)$ suggest that adult target levels for 17-OHP should be 400-1200 ng/dL. However, in young adult females interested in maintaining fertility, 17-OHP should be administered at a lower level $(<800 \mathrm{ng} / \mathrm{dL})(6,8)$. As previously stated, progesterone from the adrenal gland impairs fertility in females. Casteras et al. (52) reported that in their patients, they maintained a low serum progesterone level $(<0.6 \mathrm{ng} / \mathrm{mL})$ during the follicular phase, yet their patient pregnancy rate was $91 \%$ which is similar to that of the normal population. Therefore, this level of progesterone in the follicular phase may be recommended to adult females who want to become pregnant.

In adult males without TARTs, rather high levels of serum 17-OHP $(<2,500 \mathrm{ng} / \mathrm{dL})$ are acceptable. When very high testosterone levels are produced by the adrenal gland, adrenal androgen suppresses LH and FSH, resulting in testicular atrophy and infertility in adult males. Auchus (7) suggested that the measurement of androstenedione may be useful in determining whether testosterone in an adult male is derived from the testes (normal function) or the adrenal gland (compensatory and/or abnormal function). According to this study, if the androstenedione to testosterone ratio is $>0.5$, testosterone is mainly derived from the adrenal gland, while if this ratio is $<0.2$, the testosterone is mainly derived from the testes. In addition, serum levels of LH and FSH also affect fertility in adult males. King et al. (53) reported that an elevated FSH level is associated with TARTs and a suppressed LH level is a marker for oligospermia, therefore routine measurement of LH and FSH levels should be carried out in male patients.

\section{Glucocorticoid and Mineralocorticoid Treatment in Adolescents and Adults}

In children, hydrocortisone (HC) is used because long-acting glucocorticoids have stronger growth-suppressive effects compared with HC.
If patients with 21-OHD are well controlled, the HC regimen from childhood should be continued into adolescence and adulthood. However, disease control becomes difficult during puberty. During puberty, secretion of sex steroids, growth hormone, and insulinlike growth factor-1 increase. The increase of these hormones inhibits $11 B$ hydroxysteroid dehydrogenase type 1 activity $(54,55)$ which mainly metabolizes inactive cortisone to active cortisol. Secondly, high levels of growth hormone and insulin like growth factor-1 at puberty increase the glomerular filtration rate, leading to cortisol clearance from kidney $(54,56)$. These findings indicate that during puberty, the dose of $\mathrm{HC}$ may need to be increased. According to the opinion of an expert (1), guidelines from Japan suggest that levels of $\mathrm{HC}$ alone can sometimes be difficult to control during puberty and thus longacting glucocorticoids may be used in pubertal patients who have almost attained adult height. Auchus (7) proposed a stepped-up therapy for adults with 21-OHD. HC is the first step of the therapy and administration three times a day is recommended. However, $\mathrm{HC}$ has a short halflife, such that a bedtime dose is not sufficient to suppress the early morning rise in ACTH and subsequent excess androgen secretion. If control of the disease is difficult using only $\mathrm{HC}$, a second long-acting glucocorticoid such as dexamethasone or predonisolone can be added before sleep at night. If, despite this regimen, control is poor, a third twice-daily dose of predonisolone should be considered. Once or twice daily dexamethasone is the final choice, since dexamethasone is prone to induce iatrogenic Cushing features. However, dexamethasone should be avoided in young adult women who hope to become pregnant, because placental 118 hydroxysteroid dehydrogenase type 2 is unable to inactivate dexamethasone, thus allowing transfer from the mother to the fetus $(3,7)$.

It has been recognized that glucocorticoid metabolism differs greatly between individuals. Consequently, dexamethasone and prednisolone 
Table 1. Dose and regimen of glucocorticoids in adolescents and adults

\begin{tabular}{lll}
\hline Glucocorticoids & \multicolumn{1}{c}{ Times } & \multicolumn{1}{c}{ Total doses of per day } \\
\hline $\mathrm{HC}$ & Three times a day & $15-30 \mathrm{mg}$ \\
$\mathrm{HC}+$ Pred $^{*}$ & Morning and evening HC** & $15-25 \mathrm{mg}$ \\
& Bedtime Pred & $1-2.5 \mathrm{mg}$ \\
$\mathrm{HC}+$ Dex $^{\#}$ & Morning and evening HC** & $15-25 \mathrm{mg}$ \\
& Bedtime Dex & $0.1-0.3 \mathrm{mg}$ \\
Pred & Twice a day & $5-10 \mathrm{mg} /$ day (start $5 \mathrm{mg}$ a day) \\
Dex & Once a day or twice a day & $0.5-1 \mathrm{mg}$ (start $0.1-0.15 \mathrm{mg}$ a day)
\end{tabular}

*Pred: predonisolone. ${ }^{* *} \mathrm{HC}$ may be used in the morning and evening when given twice as a divided dose. The evening dose of $\mathrm{HC}$ may alternatively be given in the early afternoon. "Dex: dexamethasone. Metabolism of dexamethasone is variable in individuals, so dexamethasone must be administered once or twice daily. Because dexamethasone can transfer to the fetus, dexamethasone should not be used in women who may become pregnant. When Pred or Dex are used, begin with a low dose. Adjust dose after 4 wk after evaluating clinical features and biochemical parameters.

treatments should begin at a low dose, and dose adjustment should be performed at $4 \mathrm{wk}$ after evaluating symptoms and biochemical parameters $(7,8)$. Based on several reports, current commonly-used treatment regimens in adolescents and adults are summarized in Table 1.

Most patients diagnosed during childhood are treated with mineralocorticoids in combination with glucocorticoids. As mentioned previously, an excess of mineralocorticoids causes hypertension; thus, blood pressure, serum potassium, and plasma renin activity should be closely monitored. There are some reports stating that the mineralocorticoid dosage in some adult patients with SW could be gradually decreased or no longer be needed $(1,3)$.

\section{Conclusion}

Management targets change as a patient passes from childhood to adolescence and adulthood. In adolescents and adults, longterm side-effects of glucocorticoids should be minimized and androgen excess should be adequately suppressed to maintain fertility and to prevent metabolic consequences. Tumor prevention is also a concern.

To date, there has not been a definitive protocol covering the transition from childhood to adolescence and adult care. The best approach includes the involvement of pediatric and adult endocrinologists, health care staff, patients, and their families.

Conflict of interest: The author has no conflict to interest to disclose.

\section{Acknowledgement}

This study was supported by Health and Labor Sciences Research Grants, Research on Intractable Diseases, Research Committee on Disorders of Adrenal Hormones from the Ministry of Health, Labor, and Welfare, Japan (Grant Number: 29080201).

\section{References}

1. Ishii T, Anzo M, Adachi M, Onigata K, Kusuda S, Nagasaki K, et al. Mass Screening Committee Japanese Society for Pediatric Endocrinology Japanese Society for Mass Screening. Guidelines for diagnosis and treatment of 
21-hydroxylase deficiency (2014 revision). Clin Pediatr Endocrinol 2015;24: 77-105. [Medline] [CrossRef]

2. Morikawa S, Nakamura A, Fujikura K, Fukushi M, Hotsubo T, Miyata J, et al. Results from 28 years of newborn screening for congenital adrenal hyperplasia in sapporo. Clin Pediatr Endocrinol 2014;23: 35-43. [Medline] [CrossRef]

3. Speiser PW, Azziz R, Baskin LS, Ghizzoni L, Hensle TW, Merke DP, et al. Endocrine Society. Congenital adrenal hyperplasia due to steroid 21-hydroxylase deficiency: an Endocrine Society clinical practice guideline. J Clin Endocrinol Metab 2010;95: 4133-60. [Medline] [CrossRef]

4. Parsa AA, New MI. Steroid 21-hydroxylase deficiency in congenital adrenal hyperplasia. J Steroid Mol Biol 2017;165 (Pt A): 2-11.[CrossRef]

5. Xu Z, Chen W, Merke DP, McDonnell NB. Comprehensive mutation analysis of the CYP21A2 gene: an efficient multistep approach to the molecular diagnosis of congenital adrenal hyperplasia. J Mol Diagn 2013;15: 745-53. [Medline] [CrossRef]

6. Merke DP, Poppas DP. Management of adolescents with congenital adrenal hyperplasia. Lancet Diabetes Endocrinol 2013;1: 341-52. [Medline] [CrossRef]

7. Auchus RJ. Management considerations for the adult with congenital adrenal hyperplasia. Mol Cell Endocrinol 2015;408: 190-7. [Medline] [CrossRef]

8. El-Maouche D, Arlt W, Merke DP. Congenital adrenal hyperplasia. Lancet 2017;390: 2194-210. [Medline] [CrossRef]

9. Finkielstain GP, Kim MS, Sinaii N, Nishitani M, Van Ryzin C, Hill SC, et al. Clinical characteristics of a cohort of 244 patients with congenital adrenal hyperplasia. J Clin Endocrinol Metab 2012;97: 4429-38. [Medline] [CrossRef]

10. Han TS, Conway GS, Willis DS, Krone N, Rees DA, Stimson RH, et al. United Kingdom Congenital Adrenal Hyperplasia Adult Study Executive (CaHASE). Relationship between final height and health outcomes in adults with congenital adrenal hyperplasia: United Kingdom congenital adrenal hyperplasia adult study executive (CaHASE). J Clin Endocrinol Metab 2014;99: E1547-55. [Medline] [CrossRef]
11. Falhammar H, Frisén L, Hirschberg AL, Norrby C, Almqvist C, Nordenskjöld A, et al. Increased cardiovascular and metabolic morbidity in patients with 21-hydroxylase deficiency: a Swedish population-based national cohort study. J Clin Endocrinol Metab 2015;100: 3520-8. [Medline] [CrossRef]

12. Bouvattier C, Esterle L, Renoult-Pierre P, de la Perrière AB, Illouz F, Kerlan V, et al. Clinical outcome, hormonal status, gonadotrope axis, and testicular function in 219 adult men born with classic 21-hydroxylase deficiency. A French National Survey. J Clin Endocrinol Metab 2015;100: 2303-13. [Medline] [CrossRef]

13. Harrington J, Peña AS, Gent R, Hirte C, Couper J. Adolescents with congenital adrenal hyperplasia because of 21-hydroxylase deficiency have vascular dysfunction. Clin Endocrinol (Oxf) 2012;76: 837-42. [Medline] [CrossRef]

14. Sartorato P, Zulian E, Benedini S, Mariniello $\mathrm{B}$, Schiavi F, Bilora F, et al. Cardiovascular risk factors and ultrasound evaluation of intimamedia thickness at common carotids, carotid bulbs, and femoral and abdominal aorta arteries in patients with classic congenital adrenal hyperplasia due to 21-hydroxylase deficiency. J Clin Endocrinol Metab 2007;92: 1015-8. [Medline] [CrossRef]

15. Matsubara Y, Ono M, Miyai K, Takizawa F, Takasawa K, Onishi T, et al. Longitudinal analysis of growth and body composition of Japanese 21-OHD patients in childhood. Endocr J 2013;60: 149-54. [Medline] [CrossRef]

16. Takishima S, Nakajima K, Nomura R, TsujiHosokawa A, Matsuda N, Matsubara Y, et al. Lower body weight and BMI at birth were associated with early adiposity rebound in 21-hydroxylase deficiency patients. Endocr J 2016;63: 983-90. [Medline] [CrossRef]

17. Sarafoglou K, Forlenza GP, Yaw Addo O, Kyllo J, Lteif A, Hindmarsh PC, et al. Obesity in children with congenital adrenal hyperplasia in the Minnesota cohort: importance of adjusting body mass index for height-age. Clin Endocrinol (Oxf) 2017;86: 708-16. [Medline] [CrossRef]

18. Koyama S, Ichikawa G, Kojima M, Shimura N, Sairenchi T, Arisaka O. Adiposity rebound and the development of metabolic syndrome. 
Pediatrics 2014;133: e114-9. [Medline] [CrossRef]

19. Koyama S, Sairenchi T, Shimura N, Arisaka O. Association between timing of adiposity rebound and body weight gain during infancy. J Pediatr 2015;166: 309-12. [Medline] [CrossRef]

20. Mallappa A, Sinaii N, Kumar P, Whitaker MJ, Daley LA, Digweed D, et al. A phase 2 study of Chronocort, a modified-release formulation of hydrocortisone, in the treatment of adults with classic congenital adrenal hyperplasia. J Clin Endocrinol Metab 2015;100: 1137-45. [Medline] [CrossRef]

21. Jones CM, Mallappa A, Reisch N, Nikolaou N, Krone N, Hughes BA, et al. Modified-release and conventional glucocorticoids and diurnal androgen excretion in congenital adrenal hyperplasia. J Clin Endocrinol Metab 2017;102: 1797-806. [Medline]

22. Knowles RL, Khalid JM, Oerton JM, Hindmarsh PC, Kelnar CJ, Dezateux C. Late clinical presentation of congenital adrenal hyperplasia in older children: findings from national paediatric surveillance. Arch Dis Child 2014;99: 30-4. [Medline] [CrossRef]

23. Williams RM, Deeb A, Ong KK, Bich W, Murgatroyd PR, Hughes IA, et al. Insulin sensitivity and body composition in children with classical and nonclassical congenital adrenal hyperplasia. Clin Endocrinol (Oxf) 2010;72: 155-60. [Medline] [CrossRef]

24. Saygili F, Oge A, Yilmaz C. Hyperinsulinemia and insulin insensitivity in women with nonclassical congenital adrenal hyperplasia due to 21-hydroxylase deficiency: the relationship between serum leptin levels and chronic hyperinsulinemia. Horm Res 2005;63: 270-4. [Medline]

25. Diamanti-Kandarakis E, Dunaif A. Insulin resistance and the polycystic ovary syndrome revisited: an update on mechanisms and implications. Endocr Rev 2012;33: 981-1030. [Medline] [CrossRef]

26. Lazic M, Aird F, Levine JE, Dunaif A. Prenatal androgen treatment alters body composition and glucose homeostasis in male rats. J Endocrinol 2011;208: 293-300. [Medline]

27. Cardoso RC, Veiga-Lopez A, Moeller J, Beckett
E, Pease A, Keller E, et al. Developmental programming: impact of gestational steroid and metabolic milieus on adiposity and insulin sensitivity in prenatal testosterone-treated female sheep. Endocrinology 2016;157: 522-35. [Medline] [CrossRef]

28. Bonfig W, Schwarz HP. Blood pressure, fludrocortisone dose and plasma renin activity in children with classic congenital adrenal hyperplasia due to 21-hydroxylase deficiency followed from birth to 4 years of age. Clin Endocrinol (Oxf) 2014;81: 871-5. [Medline] [CrossRef]

29. Bonfig W, Roehl FW, Riedl S, Dörr HG, Bettendorf M, Brämswig J, et al. AQUAPE CAH Study Group. Blood pressure in a large cohort of children and adolescents with classic adrenal hyperplasia (CAH) due to 21-hydroxylase deficiency. Am J Hypertens 2016;29: 266-72. [Medline] [CrossRef]

30. Claahsen-van der Grinten HL, Sweep FC, Blickman JG, Hermus AR, Otten BJ. Prevalence of testicular adrenal rest tumours in male children with congenital adrenal hyperplasia due to 21-hydroxylase deficiency. Eur J Endocrinol 2007;157: 339-44. [Medline] [CrossRef]

31. Chihaoui M, Kanoun F, Chaker F, Yazidi M, Bouchrit K, Mizouni H, et al. Testicular adrenal rest tumours in young adult males with congenital adrenal hyperplasia: prevalence and impact on testicular function. Andrologia 2016;48: 45-50. [Medline] [CrossRef]

32. Engels M, Gehrmann K, Falhammar H, Webb EA, Nordenström A, Sweep FC, et al. dsdLIFE group Gonadal function in adult male patients with congenital adrenal hyperplasia. Eur J Endocrinol 2018;178: 285-94. [Medline] [CrossRef]

33. Robin G, Decanter C, Baffet H, Catteau-Jonard S, Dewailly D. Steroid 21-hydroxylase deficiencies and female infertility: pathophysiology and management. Gynecol Obstet Fertil 2014;42: 422-8 (in French). [Medline] [CrossRef]

34. Lekarev O, Lin-Su K, Vogiatzi MG. Infertility and reproductive function in patients with congenital adrenal hyperplasia: pathophysiology, advances in management, and recent outcomes. Endocrinol Metab Clin North Am 2015;44: 705-22. [Medline] 
[CrossRef]

35. Witchel SF. Congenital adrenal hyperplasia. J Pediatr Adolesc Gynecol 2017;30: 520-34. [Medline] [CrossRef]

36. Pache TD, Chadha S, Gooren LJ, Hop WC, Jaarsma KW, Dommerholt HB, et al. Ovarian morphology in long-term androgen-treated female to male transsexuals. A human model for the study of polycystic ovarian syndrome? Histopathology 1991;19: 445-52. [Medline] [CrossRef]

37. Levin JH, Carmina E, Lobo RA. Is the inappropriate gonadotropin secretion of patients with polycystic ovary syndrome similar to that of patients with adult-onset congenital adrenal hyperplasia? Fertil Steril 1991;56: 635-40. [Medline] [CrossRef]

38. Liang YX, Liu L, Jin ZY, Liang XH, Fu YS, Gu $\mathrm{XW}$, et al. The high concentration of progesterone is harmful for endometrial receptivity and decidualization. Sci Rep 2018;8: 712. [Medline] [CrossRef]

39. Kuhnle U, Bullinger M, Schwarz HP. The quality of life in adult female patients with congenital adrenal hyperplasia: a comprehensive study of the impact of genital malformations and chronic disease on female patients life. Eur J Pediatr 1995;154: 708-16. [Medline] [CrossRef]

40. Gastaud F, Bouvattier C, Duranteau L, Brauner $\mathrm{R}$, Thibaud E, Kutten F, et al. Impaired sexual and reproductive outcomes in women with classical forms of congenital adrenal hyperplasia. J Clin Endocrinol Metab 2007;92: 1391-6 E. [Medline] [CrossRef]

41. Kaltsas GA, Korbonits M, Isidori AM, Webb JA, Trainer PJ, Monson JP, et al. How common are polycystic ovaries and the polycystic ovarian syndrome in women with Cushing's syndrome? Clin Endocrinol (Oxf) 2000;53: 493-500. [Medline] [CrossRef]

42. Stikkelbroeck NM, Hermus AR, Schouten D, Suliman HM, Jager GJ, Braat DD, et al. Prevalence of ovarian adrenal rest tumours and polycystic ovaries in females with congenital adrenal hyperplasia: results of ultrasonography and MR imaging. Eur Radiol 2004;14: 1802-6. [Medline] [CrossRef]

43. Tiosano D, Vlodavsky E, Filmar S, Weiner Z,
Goldsher D, Bar-Shalom R. Ovarian adrenal rest tumor in a congenital adrenal hyperplasia patient with adrenocorticotropin hypersecretion following adrenalectomy. Horm Res Paediatr 2010;74: 223-8. [Medline] [CrossRef]

44. Zaarour MG, Atallah DM, Trak-Smayra VE, Halaby GH. Bilateral ovary adrenal rest tumor in a congenital adrenal hyperplasia following adrenalectomy. Endocr Pract 2014;20: e69-74. [Medline] [CrossRef]

45. Peppa M, Dracopoulou-Vabouli M, Raptis SA. Bilateral adrenal myelolipomas associated With 21-hydroxylase deficiency. Endocr Pract 2010;16: 525-6. [Medline]

46. Ioannidis O, Papaemmanouil S, Chatzopoulos S, Paraskevas G, Konstantara A, Kotronis A, et al. Giant bilateral symptomatic adrenal myelolipomas associated with congenital adrenal hyperplasia. Pathol Oncol Res 2011;17: 775-8. [Medline] [CrossRef]

47. Nermoen I, Rørvik J, Holmedal SH, Hykkerud DL, Fougner KJ, Svartberg J, et al. High frequency of adrenal myelolipomas and testicular adrenal rest tumours in adult Norwegian patients with classical congenital adrenal hyperplasia because of 21-hydroxylase deficiency. Clin Endocrinol (Oxf) 2011;75: 753-9. [Medline] [CrossRef]

48. Nermoen I, Følling I, Vegge K, Larmo A, Nedrebø BG, Husebye ES, et al. Two adults with adrenal myelolioma and 21-hydroxylase deficiency. Case Rep Med 2009;2009: 916891. [CrossRef]

49. Ventura A, Brunetti G, Colucci S, Oranger A, Ladisa F, Cavallo L, et al. Glucocorticoid-induced osteoporosis in children with 21-hydroxylase deficiency. BioMed Res Int 2013;2013: 250462. [CrossRef].

50. Koetz KR, Ventz M, Diederich S, Quinkler M. Bone mineral density is not significantly reduced in adult patients on low-dose glucocorticoid replacement therapy. J Clin Endocrinol Metab 2012;97: 85-92. [Medline] [CrossRef]

51. Ceccato F, Barbot M, Albiger N, Zilio M, De Toni $\mathrm{P}$, Luisetto $\mathrm{G}$, et al. Long-term glucocorticoid effect on bone mineral density in patients with congenital adrenal hyperplasia due to 21-hydroxylase deficiency. Eur J Endocrinol 2016;175: 101-6. [Medline] [CrossRef]

52. Casteràs A, De Silva P, Rumsby G, Conway GS. 
Reassessing fecundity in women with classical congenital adrenal hyperplasia $(\mathrm{CAH})$ : normal pregnancy rate but reduced fertility rate. Clin Endocrinol (Oxf) 2009;70: 833-7. [Medline] [CrossRef]

53. King TF, Lee MC, Williamson EE, Conway GS. Experience in optimizing fertility outcomes in men with congenital adrenal hyperplasia due to 21 hydroxylase deficiency. Clin Endocrinol (Oxf) 2016;84: 830-6. [Medline] [CrossRef]

54. Charmandari E, Brook CG, Hindmarsh PC. Classic congenital adrenal hyperplasia and puberty. Eur J Endocrinol 2004;151(Suppl 3):
U77-82 Review. [Medline] [CrossRef]

55. Charmandari E, Hindmarsh PC, Johnston A, Brook CG. Congenital adrenal hyperplasia due to 21-hydroxylase deficiency: alterations in cortisol pharmacokinetics at puberty. J Clin Endocrinol Metab 2001;86: 2701-8. [Medline] [CrossRef]

56. Charmandari E, Pincus SM, Matthews DR, Johnston A, Brook CG, Hindmarsh PC. Sexual dimorphism in the synchrony of joint growth hormone and cortisol dynamics in children with classic 21-hydroxylase deficiency. J Pediatr Endocrinol Metab 2003;16: 1119-30. [Medline] [CrossRef] 